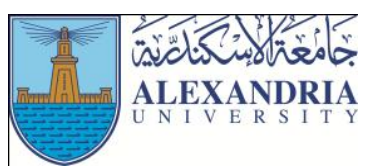

\author{
Journal of Applied Sports Science \\ April 2017, Volume 7, No. 1 \\ www.jass.alexu.edu.eg
}

\title{
The Effect of Bybee Method Applying for Structural Learning on Karate Sport Skills
}

\author{
Mohamed Ahmed Abdulmohsen Mahmoud ${ }^{1}$ \\ ${ }^{1}$ Assistant Professor, Faculty of Physical Education for Men, Helwan University, Egypt
}

\begin{abstract}
According to many learning theories based on the philosophy of knowledge building and information including a structural learning method of Bybee who used constructive philosophy which emphasizes learning based on understanding through intellectual engagement of learners and learner acquisition of knowledge depending on experiences. This method based on a set of assumptions that learning new knowledge-building process through learner mental effort to reach discovery knowledge himself in light of expectations by a certain assumptions to solve problems depending on themselves.
\end{abstract}

\section{Introduction}

A ccording to many learning theories based on the philosophy of knowledge building and information including a structural learning method of Bybee who used constructive philosophy which emphasizes learning based on understanding through intellectual engagement of learners and learner acquisition of knowledge depending on experiences. This method based on a set of assumptions that learning new knowledge-building process through learner mental effort to reach discovery knowledge himself in light of expectations by a certain assumptions to solve problems depending on themselves.

This type of learning builds meaning to what pupils need and develop their confidence in problems solving, they rely on themselves, not waiting for someone to tell them the solution, and that the learner does not only build new knowledge through own activities but also discussing the art of gloss with others and dialogue between him and them and tribal knowledge is a prerequisite in learning process (Samar Abdul Hamid Desouky, 2016) (1995, Wheatly, et al)

Hence Mohamed Moustafa Alseidy (2015)confirms that Bybee method for structural learning, depends on the perception resulted from the interaction of accumulated preceded knowledge and new knowledge, so stability will be realized by Mohamed Moustafa Alseidy (2015) practicing.
As each of Mountaser Mohamed Abdel Latif Hamdan (2014) and Heba Mohamed NurAbdulsabour (2012) confirmed the model learning using learning method for Bybee structure learning based on four phases (the invite, then explore , suggest solutions and explanations are followed by action), advocacy Invitation stage depend on the students ' attention and participation in the activity through showing some pictures and ask some questions for reflection on condition this activity link information and previous experience they have, with encouragement and motivation, either Exploration stage Explore stage, challenging the capacity of students to try to get answers to questions.

Through observation, measurement, experimentation, and solve problems by collecting information and perform the activity and teacher guidance and encouragement with the dialogue and the exchange of information following this stage of proposing solutions and explanations Propose Solutions and Explanations Stage here and correct the misconceptions are modified the perceptions of others right through the discussion of the proposed solutions and interpret these proposals, either Take action Stage Action phase is the application the teacher giving students enough time to apply what they have learned during their cooperation, have encounter new information leads to New call (Montasser Abdellatif Mohamed Hamdan, 2014) (Heba Mohamed Abdelsabour 2012) (http://www.rasheed.ws/forums/index.php?showtopic=5 385) 
Bybee method for structural learning known as that model consists of five phases of training used by the teacher with his students and aims to build scientific knowledge or skill pupil himself through the survey process that lead to learning and the development of many scientific concepts and practical skills and these stages are

1- Engagement, suspense stage

2- Exploration stage

3- Explanation, solutions suggesting stage

4- Elaboration stage

5- Evaluation and procedures stage

http://www.rasheed.ws/forums/index.php?showtopic=5 $385)($

as a coach of Karate(he has the black bent "5 Dan" and a teacher he noticed the traditional teaching methods to prepare pupils especially when imparting karate skills, leading to low student performance in karate and illustrated by tracing calendar for students throughout the school year, the researcher attributed to the traditional teaching method that relies on style and form May make the pupils rely entirely on the teacher, that's what invited researcher to find new base for teaching and learning for Bybee method for structural learning as a replacement for traditional learning method to cope with scientific development to learn karate skills among students, to develop thinking and how much information it gives a chance to students more involved and active effort and interact with the educational process so that the active participation of the pupils develop their self reliance and self and reach the best results in operation Tutorials, which could lead to learning.

\section{Research Aim}

Research aims to:

1-Identify the effect of using Bybee method for structural learning for learn karate skills and compared to the traditional way of pupils

2-Identify the differences in the rates of improvement groups (control, experimental) groups in karate skills education for pupils

\section{Research Hypotheses}

-There is a significant statistical differences between pre-post measures with the experimental group student who studied with Bybee model of structural learning , and grades of pupils who studied with the traditional method in developing karate skills clearly favor to experimental group.

-There is a significant statistical differences between post -measures with the experimental group student who studied with Bybee model of structural learning and grades of the control group pupils who studied with studied with the traditional method in developing karate skills clearly favor to experimental group.

\section{Research Procedures}

\section{Research method:}

The researcher utilized the experimental method because its appropriated to the research nature, with a control \&experimental groups

\section{Research community:}

The research community has been chosen the way of intentional pupils for the school year $(2016$ - $2017 \mathrm{~m})$ from Hamada Tantawi experimental language Department of Sanouris in Fayoum governorate, 80 pupils.

\section{The sample}

Search sample was selected arbitrarily from the research community (20) of each group (control, experimental) total (40) students as a percentage $(50 \%)$ From the research community as beginners in karate, and a number were selected (20) students to conduct surveys and legalize the test in question has been selected first grade secondary school Hamada Tantawi experimental language.

\section{Homogeneity:}

Homogeneity were made between the members of a sample search on age, height and weight and the variables under consideration table (2) demonstrates consistency between respondents and researcher find search sample homogeneity (for each group separately(

Illustrated by a table (1) Torsioncoefficients sample basic search selected variables have been limited $( \pm 3)$ indicating the homogeneity of the sample in the variables under consideration 
Table (1)

Statistical description search sample on age, height and weight $(\mathrm{N}=20)$

\begin{tabular}{|c|c|c|c|c|c|}
\hline Variables & Measurement unit & Mean & Standard Deviation & Median & Torsion coefficient \\
\hline Age & Year & 13.45 & 2.31 & 13 & -0.71 \\
\hline Height & CM & 145.00 & 4.10 & 144 & 0,73 \\
\hline Weight & KG & 41.25 & 5.64 & 40 & 0.66 \\
\hline
\end{tabular}

Data collection tools:

The researcher relied on the appropriated search tools to realize research aims as follow:

\section{Measuring tools and devices}

Alrastamitr device to measure length in centimeters*

Medical scales to measure weight in kilogram*

Tape measure in centimeters*

\section{Karate skills tests:}

Test is used to measure the skills of karate under discussion as follow:

And measured the performance skills of karate by (5) arbitrators from Karate Instructor and black belt (5) annex (1) and the degree of each skill score of (10) temperature commensurate and performance skills to score an average of five degrees and these skills are as follows-: And measured the performance skills of karate by (5) arbitrators from Karate Instructor and black belt (5) annex (1) and the degree of each skill scoreof (10) temperature commensurate and performance skills to score an average of five degrees and these skills are as follows:

\section{Karate skills:}

*kibadshistance(Kiba-Dachi)

* Front stance (Zenkutsu-Dachi)

*Upward connection(Achi-Uke)

*Downward connection (Gadan-Barai)

*Connection with the sword of the hand(Shuot-Uke)

*Connection from the inside out(Uchi-Uke)

*Connection from the outside in(Soto-Uke)

*Straight punch(ChokuZukiTsuk)

*Punching a fist-advanced(Kizami- Zuki)

*Back fist strike (UrakenUchi)
*Opposite attack with fists (Chaku-Zuki)

* Front kick (Mae-Gari)

*Ring Kicking (Mawashi-Gare)

*Side kicks(Yoko-Geri)

*Back Beating (Ushiro-Gare)

*Configurable fighting(Upon-Komotee)

\section{Institute Bybee method for suggested structural learning}

After seeing the previous scientific research and reference (1) (2) (3) (4) (5) (6) in the same area of the current study and interviews with specialists can identify the basic principles for the establishment Bybee method for structural learningas well as devices and tools used, as determined

\section{Bybee method for structural learningTime dividing :}

Application of Bybee method for structural learning period (12) wk (3) weekly units total (36) educational unit, a unit (60) minutes are distributed as follows:

(5m) administrative actions , general physical preparation.-

(15m)Special physical preparation-

35m)Major part(-

\section{Exploratory study}

An exploratory study was conducted on 2/10/2016 m with the aim of experimenting with structural method units and reached a suitable unit for their content, know the correct sequence for each method of teaching methods

\section{Experiment steps:}

\section{Two groups pre-measures}

Researcher carried out karate skills measurements on a sample basic search to find equivalence between the two groups (control, experimental) each with a strength of 
20 pupils, the researcher said these measurements are pre- measurements of groups

Table 2 shows no statistical differences of pre-measures between groups (control, experimental) in karate skills, so that the calculated value $(\mathrm{T})$ is greater than the value $(\mathrm{T})$ at the table indication (0.05), indicating the equivalence between the two groups in the tribal standard groups (control, experimental)

Table (2)

Indication of the differences between the pre- measurements of the teaching skills of equivalence between the two groups (control, experimental) in karate skills $(\mathrm{N} 1=\mathrm{n} 2=20)$

\begin{tabular}{|c|c|c|c|c|c|}
\hline \multirow[b]{2}{*}{ Statistical transactions } & \multicolumn{2}{|c|}{ Control group } & \multicolumn{2}{|c|}{ Experimental group } & \multirow{2}{*}{ T Value } \\
\hline & $\mathbf{S}$ & $\mathbf{A}$ & $\mathbf{S}$ & $\mathbf{A}$ & \\
\hline kibadshistance (Kiba-Dachi) & 4.25 & 0.65 & 4.21 & 0.61 & 0.20 \\
\hline Height Front stance (Zenkutsu-Dachi) & 4.20 & 0.58 & 4.23 & 0.69 & 0,15 \\
\hline Upward connection(Achi-Uke & 4.15 & 0.52 & 4.10 & 0.56 & 0.24 \\
\hline Downward connection (Gadan-Barai) & 4.19 & 0.62 & 4.10 & 0.56 & 0.05 \\
\hline $\begin{array}{l}\text { Connection with the sword of the } \\
\text { hand(Shuot-Uke) }\end{array}$ & 4.25 & 0.58 & 4.20 & 0.56 & 0.15 \\
\hline $\begin{array}{l}\text { Connection from the inside out(Uchi- } \\
\text { Uke) }\end{array}$ & 4.31 & 0.53 & 4.22 & 0.60 & 0.18 \\
\hline Connection from the outside in(Soto-Uke) & 4.18 & 0.74 & 4.28 & 0.55 & 0.09 \\
\hline Straight punch (ChokuZukiTsuk) & 4.08 & 0.72 & 4.20 & 0.68 & 0.09 \\
\hline Punching a fist-advanced(Kizami- Zuki) & 4.11 & 0.45 & 4.10 & 0.62 & 0.27 \\
\hline Back fist strike (UrakenUchi) & 4.31 & 0.64 & 4.15 & 0.50 & 0.20 \\
\hline Opposite attack with fists ( Chaku-Zuki) & 4.26 & 0.52 & 4.25 & 0.62 & .31 \\
\hline Front kick (Mae-Gari) & 4.10 & 0.63 & 4.21 & 0.50 & 0.10 \\
\hline Ring Kicking (Mawashi-Gare) & 4.28 & 0.55 & 4.12 & 0.59 & 0.29 \\
\hline Side kicks(Yoko-Geri) & 4.17 & 0.38 & 4.23 & 0.52 & 0.23 \\
\hline Back Beating (Ushiro-Gare) & 4.20 & 0.41 & 4.20 & 0.42 & 0.14 \\
\hline Configurable fighting(Upon-Komotee) & 4.24 & 0.51 & 4.18 & 0.45 & 0.18 \\
\hline Downward connection (Gadan-Barai) & 4.19 & 0.62 & 4.21 & 0.50 & 0.05 \\
\hline
\end{tabular}

T value with $0.05=2.93$

\section{Applying the suggested program:}

\section{The experimental group}

Bybee is a learning method for a structural learning ( annex 2) from 16/10/2016-11/12/2016 to learn karate, and has been teaching units using steps of constructive learning Bybee method through raising the problem or by viewing the pictures and ask the teacher some questions to think about with induced to solve them through experimentation, exercises and ask them to be the process of discussion and dialogue with findings during each stage performance with redirect questions Linked to technical points of skill to choose the best pupils urges solutions to the educational situation, education school Hamada Tantawi experimental language

\section{The control group:}

-Traditional program were applied (explaining the teacher) to learn karate skills being examined from $16 / 10 / 2016-11 / 12 / 2016$ by

View a sample of the performance of the skill.

- Give an idea of the skill and technical aspects associated with them (when to use its advantages), and legal aspects associated with it.

- Student performance of skill and practical exercises on skill to improve performance. 
- educating in the stadium (yard) school Hamada

Tantawi experimental language.

\section{Post measure:}

After finishing program applying researcher carried out the post measure on two days in 12/12/2016.

\section{Results Discussion}

Table (3) shows that there is a significant statistical differences between pre-post measures with the control group in Karate skills favor to the post measure, hence calculated $(\mathrm{T})$ value is more than $(\mathrm{T})$ table with $(0.05)$

Table (3)

The difference indication between pre-post measures with the control groupin Karate skills $(\mathrm{N}=20)$

\begin{tabular}{|c|c|c|c|c|c|}
\hline \multirow[b]{2}{*}{ Statistical transactions } & \multicolumn{2}{|c|}{ Control group } & \multicolumn{2}{|c|}{ Experimental group } & \multirow{2}{*}{ T Value } \\
\hline & $\mathbf{S}$ & $\mathbf{A}$ & $\mathbf{S}$ & $\mathbf{A}$ & \\
\hline kibadshistance (Kiba-Dachi) & 4.25 & 0.65 & 6.30 & 0.86 & $8.54 *$ \\
\hline Height Front stance (Zenkutsu-Dachi) & 4.20 & 0.58 & 6.15 & 0.63 & $9.75^{*}$ \\
\hline Upward connection(Achi-Uke & 4.15 & 0.52 & 6.45 & 0.95 & $9.58^{*}$ \\
\hline Downward connection (Gadan-Barai) & 4.19 & 0.62 & 6.35 & 0.72 & $9.82 *$ \\
\hline $\begin{array}{l}\text { Connection with the sword of the } \\
\text { hand(Shuot-Uke) }\end{array}$ & 4.25 & 0.58 & 6.14 & 0.69 & $9.54 *$ \\
\hline $\begin{array}{l}\text { Connection from the inside out(Uchi - } \\
\text { Uke) }\end{array}$ & 4.31 & 0.53 & 6.38 & 0.70 & $10.35^{*}$ \\
\hline Connection from the outside in(Soto-Uke) & 4.18 & 0.74 & 6.28 & 0.81 & $9.17 *$ \\
\hline Straight punch (ChokuZukiTsuk) & 4.08 & 0.72 & 6.10 & 0.75 & $8.42 *$ \\
\hline Punching a fist-advanced(Kizami- Zuki) & 4.11 & 0.45 & 6.24 & 0.68 & $11.83^{*}$ \\
\hline Back fist strike (UrakenUchi) & 4.31 & 0.64 & 6.35 & 0.79 & $8.87 *$ \\
\hline Opposite attack with fists ( Chaku-Zuki) & 4.26 & 0.52 & 6.20 & 0.81 & $8.82 *$ \\
\hline Front kick (Mae-Gari) & 4.10 & 0.63 & 6.25 & 0.68 & $9.77 *$ \\
\hline Ring Kicking (Mawashi-Gare) & 4.28 & 0.55 & 6.15 & 0.77 & $8.50^{*}$ \\
\hline Side kicks(Yoko-Geri) & 4.17 & 0.38 & 6.18 & 0.72 & $11.17^{*}$ \\
\hline Back Beating (Ushiro-Gare) & 4.20 & 0.41 & 6.20 & 0.71 & $10.53^{*}$ \\
\hline Configurable fighting(Upon-Komotee) & 4.24 & 0.51 & 6.12 & 0.78 & $8.55^{*}$ \\
\hline Downward connection (Gadan-Barai) & 4.25 & 0.65 & 6.30 & 0.86 & $8.54^{*}$ \\
\hline
\end{tabular}

T Table value with $(0.05)=2.093$

Table(4) shows a significant statistical differences between pre-post measures with the experimental group in Karate skills favor to post -measure, hence calculated $\mathrm{T}$ value is more than $\mathrm{T}$ table with (0.05) 
Table (4)

Indication of differences between pre-post measures of the experimental group in Karate Skills (N=20)

\begin{tabular}{|c|c|c|c|c|c|}
\hline \multirow[b]{2}{*}{ Statistical transactions } & \multicolumn{2}{|c|}{ Pre-measure } & \multicolumn{2}{|c|}{ Post measure } & \multirow{2}{*}{ T Value } \\
\hline & $\mathbf{S}$ & $\mathbf{A}$ & $\mathbf{S}$ & $\mathbf{A}$ & \\
\hline kibadshistance (Kiba-Dachi) & 4.21 & 0.61 & 8.19 & 0.79 & $18.09 *$ \\
\hline Height Front stance (Zenkutsu-Dachi) & 4.23 & 0.69 & 8.10 & 0.81 & $16.83 *$ \\
\hline Upward connection(Achi-Uke & 4.10 & 0.60 & 8.04 & 0.98 & $14.59^{*}$ \\
\hline Downward connection (Gadan-Barai) & 4.20 & 0.56 & 8.11 & 0.82 & $17.00 *$ \\
\hline $\begin{array}{l}\text { Connection with the sword of the } \\
\text { hand(Shuot-Uke) }\end{array}$ & 4.22 & 0.60 & 8.20 & 0.79 & $17.30^{*}$ \\
\hline $\begin{array}{l}\text { Connection from the inside out(Uchi - } \\
\text { Uke) }\end{array}$ & 4.28 & 0.55 & 7.86 & 0.91 & $15.56^{*}$ \\
\hline Connection from the outside in(Soto-Uke) & 4.20 & 0.68 & 7.94 & 0.82 & $16.20^{*}$ \\
\hline Straight punch (ChokuZukiTsuk) & 4.10 & 0.62 & 8.08 & 0.93 & $15.31^{*}$ \\
\hline Punching a fist-advanced(Kizami- Zuki) & 4.15 & 0.50 & 7.88 & 0.83 & $18.65^{*}$ \\
\hline Back fist strike (UrakenUchi) & 4.25 & 0.62 & 7.99 & 0.80 & $17.00 *$ \\
\hline Opposite attack with fists ( Chaku-Zuki) & 4.21 & 0.50 & 8.01 & 0.79 & $18.09^{*}$ \\
\hline Front kick (Mae-Gari) & 4.12 & 0.59 & 8.07 & 0.95 & $15.19^{*}$ \\
\hline Ring Kicking (Mawashi-Gare) & 4.23 & 0.52 & 7.98 & 0.91 & $16.30^{*}$ \\
\hline Side kicks(Yoko-Geri) & 4.20 & 0.42 & 7.89 & 0.92 & $16.77^{*}$ \\
\hline Back Beating (Ushiro-Gare) & 4.18 & .45 & 7.94 & 0.93 & $17.09^{*}$ \\
\hline Configurable fighting(Upon-Komotee) & 4.21 & 0.50 & 8.04 & 0.82 & $17.41 *$ \\
\hline Downward connection (Gadan-Barai) & 4.21 & 0.61 & 8.19 & 0.79 & $18.09 *$ \\
\hline
\end{tabular}

T table value with $(0.05)=2.093$

Table (5) shows that there is a significant statistical differences between pre-post measures with (control\& experimental)groups in Karate skills favor to post measure for the experimental group, hence calculated $\mathrm{T}$ value is more than $\mathrm{T}$ table with 0.05 
Table (5)

Indication of differences between post measures of the Teaching Methods with experimental \& control group in Karate Skills $(\mathbf{N 1}=\mathbf{N} 2=20)$

\begin{tabular}{|c|c|c|c|c|c|c|}
\hline \multirow[b]{2}{*}{$\begin{array}{l}\text { Statistical } \\
\text { transactions }\end{array}$} & \multicolumn{2}{|c|}{ Control Group } & \multicolumn{2}{|c|}{ Experimental Group } & \multirow{2}{*}{ Differences } & \multirow{2}{*}{ T Value } \\
\hline & $\mathbf{S}$ & $\mathbf{A}$ & $\mathbf{S}$ & $\mathbf{A}$ & & \\
\hline kibadshi stance (Kiba-Dachi) & 6.30 & 0.86 & 8.19 & 0.79 & 1.89 & $7.27 *$ \\
\hline Height Front stance (Zenkutsu-Dachi) & 6.15 & 0.63 & 8.10 & 0.81 & 1.95 & $8.48^{*}$ \\
\hline Upward connection(Achi-Uke & 6.45 & 0.95 & 8.04 & 0.98 & 1.59 & $5.13 *$ \\
\hline Downward connection (Gadan-Barai) & 6.35 & 0.72 & 8.11 & 0.82 & 1.76 & $7.65 *$ \\
\hline $\begin{array}{l}\text { Connection with the sword of the } \\
\text { hand(Shuot-Uke) }\end{array}$ & 6.14 & 0.69 & 8.20 & 0.79 & 2.06 & $9.36^{*}$ \\
\hline $\begin{array}{l}\text { Connection from the inside out(Uchi - } \\
\text { Uke) }\end{array}$ & 6.38 & 0.70 & 7.86 & 0.91 & 1.59 & $5.13^{*}$ \\
\hline $\begin{array}{c}\text { Connection from the outside in(Soto- } \\
\text { Uke) }\end{array}$ & 6.28 & 0.81 & 7.94 & 0.82 & 1.66 & $7.55^{*}$ \\
\hline Straight punch (ChokuZukiTsuk) & 6.10 & 0.75 & 8.08 & 0.93 & 1.98 & $7.62 *$ \\
\hline $\begin{array}{l}\text { Punching a fist-advanced(Kizami- } \\
\text { Zuki) }\end{array}$ & 6.24 & 0.68 & 7.88 & 0.83 & 1.64 & $7.45 *$ \\
\hline Back fist strike (UrakenUchi) & 6.35 & 0.79 & 7.99 & 0.80 & 1.64 & $7.13^{*}$ \\
\hline $\begin{array}{c}\text { Opposite attack with fists ( Chaku- } \\
\text { Zuki) }\end{array}$ & 6.20 & 0.81 & 8.01 & 0.79 & 1.81 & $7.87 *$ \\
\hline Front kick (Mae-Gari) & 6.25 & 0.68 & 8.07 & 0.95 & 1.82 & $7.00^{*}$ \\
\hline Ring Kicking (Mawashi-Gare) & 6.15 & 0.77 & 7.98 & 0.91 & 1.83 & $7.96^{*}$ \\
\hline Side kicks(Yoko-Geri) & 6.18 & 0.72 & 7.89 & 0.92 & 1.71 & $7.77 *$ \\
\hline Back Beating (Ushiro-Gare) & 6.20 & 0.71 & 7.94 & 0.93 & 1.74 & $7.91 *$ \\
\hline $\begin{array}{l}\text { Configurable fighting(Upon- } \\
\text { Komotee) }\end{array}$ & 6.12 & 0.78 & 8.04 & 0.82 & 1.92 & $8.73^{*}$ \\
\hline
\end{tabular}

T Table value with $(0.05)=2.093$

\section{Results Discussion}

Tables $(3,4)$ show that there is a significant statistical differences between pre-post measure for both of (control \&experimental) groups in Karate favor to post measure for the two groups.

The researcher attributed these results to the positive impact of traditional program to control group, application form and style which includes explaining and clarifying performance skill learning points with debugging which contributes to improve the pupils also includes explaining the technical and legal information related to skills The researcher attributed these results to the positive impact of traditional program to control group, application form and style which includes explaining and clarifying performance skill learning points with debugging which contributes to improve the pupils also includes explaining the technical and legal information related to skills.

This is consistent with the results of each of NajlaHusni Allah (2011) and MI TalatTolbaAfifi (2011), where research results showed improvement in the control group as a result of implementing the traditional program (explanation and form.( This is consistent with the results of each of NajlaHusni Allah (2011) and MaiTalatTolbaAfifi (2011), where research results showed improvement in the control group as a result of implementing the traditional program (explanation and form)

The researcher attributed the positive impact of the (structural learning) program with the experimental group to applying of Bybee method for structural 
learning, hence it includes -in its concept more than learning style such as discovering, solve problems

This diversity stimulates pupils and reduces their sense of boredom and creates the kind of attention and interest among students in teach karate.

The researcher also attributes progress in the skills level under discussion with the experimental group (structural learning) to the structural strategy nature, it distinguished with Skill segmentation according to stages (advocacy, exploration, proposing solutions, and action(This is done in the form of kinetic task performed by the student at each of these stages, with the seeker by throwing a bunch of questions that are compatible with every stage in the form of Visual stimuli to optimize access for performance and is under discussion and dialogue between pupil and teacher colleagues.

This is consistent with the Samar Abdul Hamid Dessouky (2016) and MI TalatTolbaAfifi (2011) that dialogue between members of the group working on creating an intellectual bonding between them and deepen their understanding in helping them to retain the information for as long as possible.

This agreed with results of Mohamed MoustafaAlyAlseidy (2015) Montaser Mohamed AbdullateifHamdan (2014)Killer (2002)whichproved the efficiency of Bybee method of structural learning for some motor skills of the selected activity type.

This results realized the research first hypothesis, as table (5) clarifies a significant statistical differences between post-measures for the two groups (control \&experimental) in Karate favor to experimental group.

The researcher attributed the positive impact of the (structural learning) program to applying of Bybee method for structural learning, For its performance analysis skills, it also helps to remember their parts through student information retrieval reached by himself through his experience, and the presentation of the article through the questions and how to correct scientific method formulated and addressed to several hubs and containing scientific terms associated with skills and technical skills through dialogue anddiscussion,

As well as immediate positive reinforcement and by answering questions until sub optimal performance to answer the main question this helps install information for the longest period of time.
This is consistent with what HebaAbdelsabourMohamed Nur (2012) that through the pupil can debate to gather as much information about skill learned through feedback from fellow students and ideas converge and therefore reach the proper performance and conformity of indicated all research results of NajlaaHusni Allah (2011), MaiTalatTolbaAfifi (2011).

The researcher attributes the experimental group over the control group for what Bybee method of structural learning distinguishing with its four stages ,

It also considers that this new method in the education process in terms of increasing the time available for the application, it also has four stages through both targeted and detection method of application and problem solving techniques in teaching, which depends on the learner's acquisition of knowledge through experience, besides it suits all ages and levels, It also considers that this new method in the education process in terms of increasing the time available for the application, it also has four stages through both targeted and detection method of application and problem solving techniques in teaching, which depends on the learner's acquisition of knowledge through experience, besides it suits all ages and levels.

And gives a wie field for creativity and innovation by using the techniques in education technology advocacy.

And see all of the Ricksonc (1999), Killer (2002) Samar Abdul Hamid Dessouky (2016) and Ricksonc (1999) the usefulness of the Bybee structural learning method because it depends on correct wrong conceptions through dialogue and discussion by the teacher with students and with each other, as well as cognitive concepts that build skills and performance level is one of the best and most successful methods in teaching skills.

This results realize the second research hypothesis

\section{Results}

- Bybeemethod model for structural learning helps in increasingthe students interaction with teacher , decrease teacher effort in learning Karate skills.

- Bybeemethod program for structural learning has a positive effect in Karate with the students.

- Bybeemethod program for structural learning is better than the traditional method in learning some $s$ ' karate skills with pupils. 


\section{Recommendations}

- Interest in Bybeemethod model for structural learning as a modern models help to learn and to use in learning karate skills to pupils.

- Utilizing Bybeemethod for structural learning in learning karate skills to pupils.

- Organizing seminars \&rounds presented b professional expert in Karate by the Egyptian Karate Federation for Professional physical education teachers of Karate to give them knowledge of modern theories in training such as Bybeemethod model for structural learning .

\section{References}

1- Samar AbdulhamidDesoky(2016) Structural Learning and its In Learning OutputsFor Some Hand ball Attack Skills With Preparatory Students in Alexandria ,Unpublished PHD Thesis , Faculty of Physical Education for Girls Alexandria University ,page 13,81.

2- Mohamed MoustafaAlyAlsaidy 2015The Impact of Interaction Between "Baybee" Model for Structural Learning and Cognitive Type on Physics Understanding, Developing Scientific Search Skills With High School Students, Unpublished PHD Thesis, Faculty of Education, Kafr Elshaikh University, page 7,89 .

3- Mountaser Mohamed AbdullatteifHamdan(2014) The Impact Of Program Using The Structural Learning Model Supported With Computer on Skills Learning Sides of Handball With Beginners, Faculty of Physical Education AlmeniaUniversity,Page 12,101.
4- Mai TalaatTolbaAfify (2011) The Impact of Structural Learning on the Motor Memory , Performance Level of Basketball, Unpublished PHD Thesis, Faculty of Physical Education for Girls, Helwan University, Page 6,195.

5- Naglaa HosnyAwadAllah(2011) The Impact of Utilizing Structural Learning on the Skillful , Cognitive Studying, With some Basic Hockey Skills, Unpublished PHD Thesis Faculty of Physical Education for Girls, Cairo, Helwan University, Page 14,6.

6- Heba Abduksabor Mohamed Nour (2012)The Impact of Learning Model on Learning Some Track and Field Events In preparatory Stage, Unpublished PHD Thesis, Faculty of Physical Education for Girls, Helwan University, page 8,74.

\section{Foreign References}

1- Killer, \& H.E. : (2002), Educational Competences among history teachers in Nevada Public School. The Educational research. Journal, 13, 145-155 .

2- Ricksonc : Kenneth Bertil, : The Relationship Between Motor Learning and Reading Cognition Dissertation Abstracts International, Vol.45 No. June .1999 .

3- Wheatly, G. et al, : "Radical constructivism L As Abases for Mathematics Reform" . Paper Presented at the Annual Meeting of the North American Chapter of Mathematics Education. 1995,p45.

4-

http://www.rasheed.ws/forums/index.php?showtopic=5 385 